\title{
A Propagative Model for Simulations of Electric Fields Produced by Downward Leaders
}

\author{
Juan Ramón Hermoso ${ }^{*}, 1$, J.Montanyà̀ ${ }^{1}$, V. March ${ }^{1}$, O. van der Velde ${ }^{1}$, G. Solà ${ }^{1}$, D. Romero ${ }^{1}$, \\ B. Hermoso ${ }^{2}$ and N. Pineda ${ }^{3}$ \\ ${ }^{I}$ Electrical Engineering Department, Technological University of Catalonia, C/ Colon $n^{\circ} 1$ Terrassa (E-08222), \\ Spain \\ ${ }^{2}$ Electrical and Electronic Engineering Department, Public University of Navarre, Campus de Arrosadia, Pamplona E- \\ 31006, Spain \\ ${ }^{3}$ Metereological Servei of Catalonia, Berlin 38, Barcelona E-08029, Spain
}

\begin{abstract}
Comparisons of simulated downward negative leaders with experimental measurements are presented in this paper. In order to simplify, the leaders are considered to progress vertically and charge distributions and leader speeds can be adjusted. The results report a good agreement with Cooray's, Golde's and Hutler's proposals. In the case of Dellera's proposal (LPM) it only agrees for the last $2 \mathrm{~km}$ of the leader position. Eriksson's proposal produced good agreements but closer flash distances are not consistent with the measured lightning flash. The obtained speeds ranged between $1.15 \cdot 10^{6}$ $\mathrm{m} \cdot \mathrm{s}^{-1}$ to $2.6 \cdot 10^{4} \mathrm{~m} \cdot \mathrm{s}^{-1}$ which are consistent with those reported in literature.
\end{abstract}

Keywords: CG lightning, electric field, stepped leader speed, finite element method.

\section{INTRODUCTION}

When the electric field inside a thundercloud produced by its electrification cloud becomes high enough, an electric discharge can occur $[1,2]$. The charge structure of a thunderstorm can be very complex and can change during the storm lifetime. However, a simplified representation of the charge centers as a vertical tripolar distribution with a spherical geometry [3] is widely accepted. Some authors [4] take into account a spherical bipolar cloud charge when modeling downward leaders. In other models the cloud charge is modeled by means of ring geometries [5] or by a surface at certain potential, $50 \mathrm{MV}$ to $100 \mathrm{MV}$.

Models used to investigate the attachment of lightning to structures used to be relatively simple. These models of leaders did not consider exhaustive physics like is used in kinetic ionization models [6]. To establish a simple model for the stepped leader, some reference values for the transported charge, length, velocity, path and charge distribution should be used. All these parameters depend on each other. Reference models are the propagative models; the leader progression model (LPM) [5] and its subsequent improvement [7], the propagative model of Rizk [8] and the recently proposed by Vargas et al. [4]. Also, some valuable effort has been made to investigate the charge distribution along the leader. Recently Cooray et al. [9] considered an exponential distribution of charge along the leader channel, which seems a more real representation of the phenomenon.

*Address correspondence to this author at the $\mathrm{C} /$ Colon $\mathrm{n}^{\circ} 1$ Terrassa (E08222), Spain; Tel: +34 937398549; Fax: +34 937398225;

E-mail: hermoso@ee.upc.edu
In this paper the cloud model is assumed as a bipolar charge distribution with an ellipsoidal geometry. The model also allows addition of a third charge center, also ellipsoidal, to represent the low positive charge center below the mid level charge. The heights and extension of the charge centers are estimated from temperature soundings, radar crosssections and total lightning detections. The leader model is based on a propagative model with different values of total charge distribution on the leader according to different authors. The electric fields at ground level produced by the dynamic model are computed and compared with real measurements from the 2009 campaign (northeastern Spain), providing information about the stepped leader speed.

\section{DATA}

During summer 2009 a measurement campaign was carried out in the region of Catalonia. Vertical electric fields produced by close lightning were recorded by means of a flat plate antenna. Additionally, lightning locations of total lightning were provided by the Catalan Lightning Location Network (XDDE) [10] and LINET [11]. At that time, the XDDE was composed by two VHF interferometers of LS8000 type plus two of SAFIR 3000 type. Regarding LINET, the network had nine sensors in Spain but these were connected to the rest of the sensors in Europe. Since the XDDE network locates several tens to hundreds of sources per flash (IC flashes and in-cloud sources of CG flashes) while LINET was selected for cloud-to-ground CG data. CG data includes the location of every stroke in a flash and the estimated peak current. Besides lightning information, meteorological radar provided volumetric reflectivity profiles of the studied storm cells. In Catalonia a three Cband doppler radar network is operated by the Catalan Meteorological Service (SMC). 


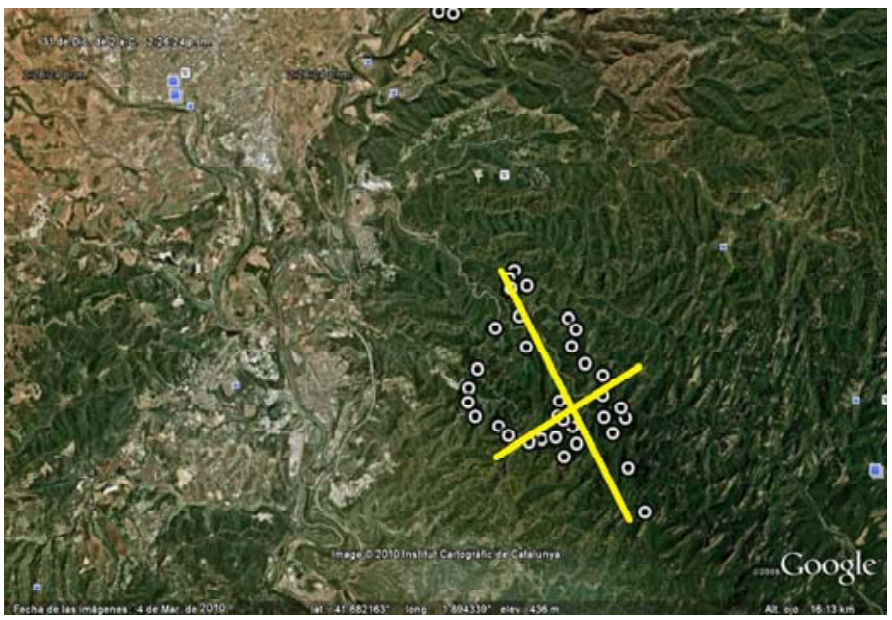

(a)

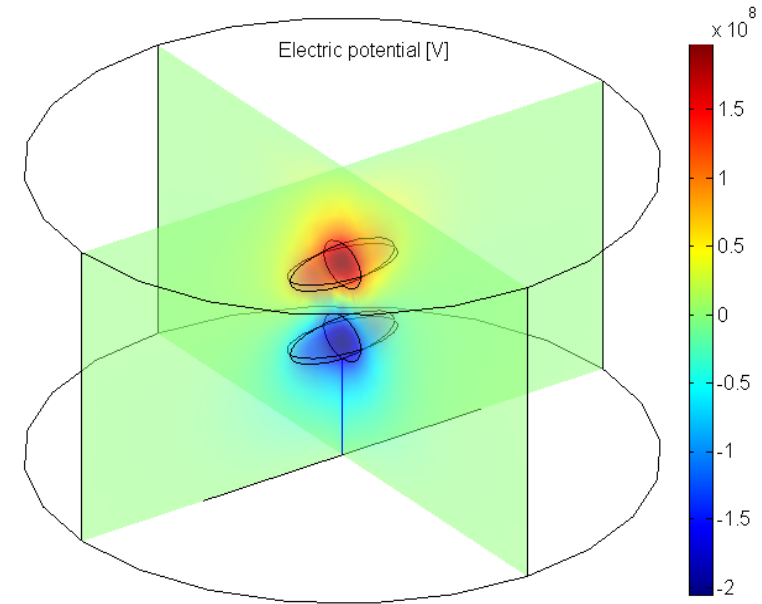

(b)

Fig. (1). (a) IC sources located by the XDDE network and the maximum and minimum axes of an ellipse that fits the sources (image generated by Google Earth). (b) COMSOL geometry of the cloud charge structure employed in this study with control volume, extended leader and court with electric potential, red is a positive charge zone and blue is the negative.

\subsection{Cloud Charge Structure}

Since the measured lightning was produced by an ordinary summer storm, the altitudes of the negative region of the cloud were assumed to correspond to the $-10{ }^{\circ} \mathrm{C}$ to -20 ${ }^{\circ} \mathrm{C}$ isotherms [12]. At the day of the field measurement, according to the closest sounding, these isotherms corresponded to the altitudes of 5 to $7.2 \mathrm{~km}$. Once the vertical range of the negative charge is obtained, its horizontal extension is adopted from the VHF cloud sources located by the XDDE VHF network. Fig. (1a) shows the IC detections associated to the studied flash. The XDDE detects negative leaders moving into a positive charge region and we will adopt as horizontal extension of the charge regions an ellipse that fits the detected sources. The axes of the ellipsoid are 6 by $3 \mathrm{~km}$ and $2.2 \mathrm{~km}$ in the vertical dimension. In this work we assume a basic vertical dipole structure where the main charge is confined in two ellipsoids with a total charge of $40 \mathrm{C}$ and $-40 \mathrm{C}$. The maximum altitude for the positive charge region above to the negative is obtained by means of radar reflectivity cross-sections. According to the radar the maximum altitude would be $11 \mathrm{~km}$.

\subsection{Stepped Leader Data}

The electric signature of a downward negative leader with a return stroke current of $-12.2 \mathrm{kA}$ at a distance of $\sim 850$ $\mathrm{m}$ approximately has been selected. These values have been adopted from the lightning location networks. We assume that the flash location could be about $800 \mathrm{~m}$ to $900 \mathrm{~m}$. For the numerical simulation we assume the lightning channel to be vertical.

\section{MODELLING}

The numerical methods used by researchers to model leaders by means of electrostatic equations are the charge simulation method (MSC) [13] and the finite element method (FEM) [14] that allows the resolution of the Poisson equation for the electric potential $U$.
The FEM executes the spatial calculation of the problem defined by boundary conditions and uses a triangular mesh. Choice of the geometry, boundary conditions and the mesh size is a fundamental aspect to obtain an approximate result $[15,16]$. The software used was Comsol Multiphysics $3.4^{\mathrm{TM}}$ [17], the code allows to adjust the mesh size for different areas of geometry. When working with large volumes (several $\mathrm{km}$ ) this option will be very useful and will help to reduce the computing time. An object or a structure (also cloud charges and the leader) are placed inside of a surface (2D) or a control volume (3D) in which the mesh is applied and the numerical calculation is developed. This surface or control volume must be much larger than the size of the object or the structure. After the first experiences by Becerra and Cooray [18], we adopted a control volume with a cylindrical shape of $15 \mathrm{~km}$ radius and height of $15 \mathrm{~km}$.

The length of each jump for the advancement of the leader is a parameter that can be modified in the model depending on the height of the leader tip, however in this study it has been set to a constant value of $50 \mathrm{~m}$ and a $50 \mu \mathrm{s}$ interval between steps $[12,19]$. The electric field at ground level produced in this event is computed for different values of charge distribution on the leader according to the geometry in Fig. (1b), with the elliptical charge zone and cylindrical control volume, as has been previously described, and one line at ground level (zero potential) to enhance the mesh and more precise results.

\section{LEADER CHARGE DISTRIBUTION MODELS AND SIMULATIONS}

In the scientific literature there are different proposals for the charge distribution along the downward negative leader channel: uniform distrubition, uniform distribution with a point charge at the leader end, linear distribution and exponential distribution.

Here are the results for variations of electric field at ground level, depending on the height of the leader tip, produced by the progress of stepped leader for some of the most commonly used leader charge distributions. 


\subsection{Cooray's Proposal}

Cooray's proposal [9] established from the comments of several authors and various considerations the following relationship for the leader charge density:

$\rho(l)=a_{0}\left(1-\frac{l}{H-z}\right) G(z) I_{p f}+\frac{I_{p f}(a+b l)}{1+c l+d l^{2}} J(z)$

where

$G(z)=1-z / H$

$J(z)=0.3 \alpha+0.7 \beta$

$\alpha=e^{-(z-10) / 75}$

$\beta=1-z / H$

the $I_{p f}$ is the return stroke peak current in $\mathrm{kA}, z$ is the leader tip height above ground (must be over $10 \mathrm{~m}$ ), $\rho(l)$ is the charge per unit length $(\mathrm{C} / \mathrm{m}), H$ is the height of the cloud base and therefore the maximum length of the leader in meters (which must be greater than $3000 \mathrm{~m}$ ), $l$ would be the point on the channel for determining the $\rho(l)(\mathrm{L}=0$ to the tip of the leader) and the constants take the following values

$a_{0}=1.476 \cdot 10^{-5}, a=4.857 \cdot 10^{-5}$,

$b=3.9097 \cdot 10^{-6} \quad c=0.522 d=3.73 \cdot 10^{-3}$

The charge distribution along the leader is assumed to be exponentially increasing according Equ (1). The charge along the leader at different leader tip altitudes and the results obtained for the electric field variation to advance the stepped leader down to a height of $11 \mathrm{~m}$ above ground level are displayed in Fig. (2).

\subsection{Golde's Proposal}

Golde [20-22] also proposes an exponential distribution, establishing a relationship between the value of the charge density on the leader channel and the charge at the end of the channel for $\mathrm{z}=0$ (when it touches the ground).

$\rho_{l}=\rho_{l 0} e^{-z / 2}$ where $z$ is the height above the ground plane, $\lambda$ is the decay height constant, $\rho_{l 0}$ is the value of the charge density at the instant contact between the leader and land and is related to the $I_{p f}$ and the total charge transported from the Equ (8)

$\rho_{l 0}=\left[\frac{I_{p f}}{k \lambda\left(1-e^{-H / \lambda}\right)}\right]$

where $H$ is the height of the cloud base (total length of the channel). Golde uses a starting point height $(H)$ of $2500 \mathrm{~m}$, a $\lambda$ value of $1000 \mathrm{~m}$ and $k=20 \mathrm{kA} / \mathrm{C}$. In our study we keep the value of $\lambda$ but we work with $H$ of $5000 \mathrm{~m}$, and adopt the proposed Cooray of $k=25 \mathrm{kA} / \mathrm{C}$ [9]. Fig. (3) shows the results for $\Delta \mathrm{E}$ at ground level for different distances from the observation point.

\subsection{Hutzler's Proposal}

With uniform distribution: in general the simplest option is to assume that the total load is evenly distributed along the leader cannel.

$\rho_{l}=\frac{Q_{l}}{L}$

In their studies Hutzler [23], used the experimental relationship developed by Berger [24] to establish the relationship between total charge in the channel of the leader and the return stroke current.

$Q_{l}=\frac{I_{P f}}{15}$

Fig. (4) shows that the result most closely matching the real measurement is the curve obtained for the simulation at an observation point located $900 \mathrm{~m}$ from the leader channel.

With a uniform distribution plus a punctual charge at leader tip: Using a uniform charge distribution along the leader, except in its final part, which increases the charge density relative to the rest. In general, there are two alternatives, assuming the higher charge density concentrated

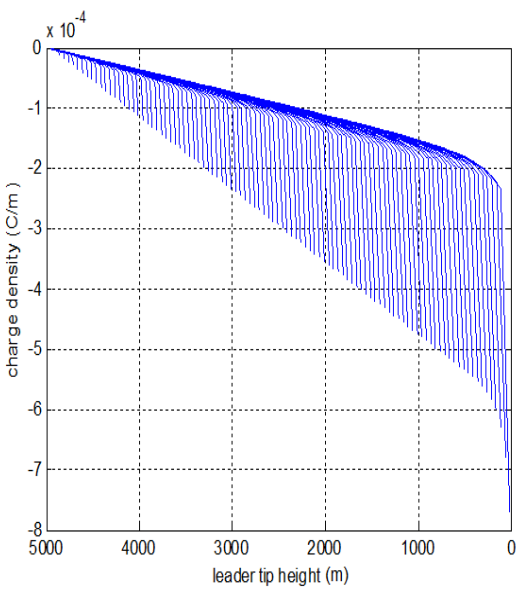

(a)

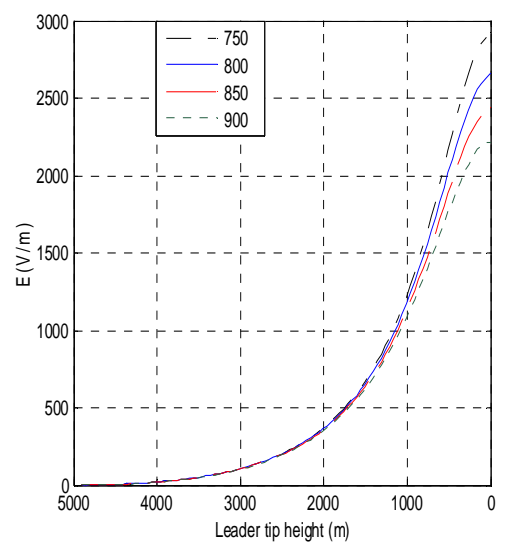

(b)

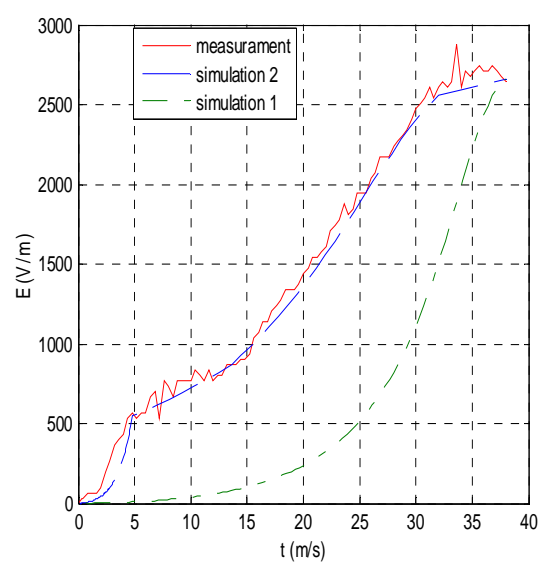

(c)

Fig. (2). Results for Cooray - exponential proposal: (a) Charge density of the leader at different heights. (b) Electric field signature of a downward leader. (c) Measured electric field signature of a downward leader at $800 \mathrm{~m}$ and simulated leaders (1) at constant speed and (2) at variable 


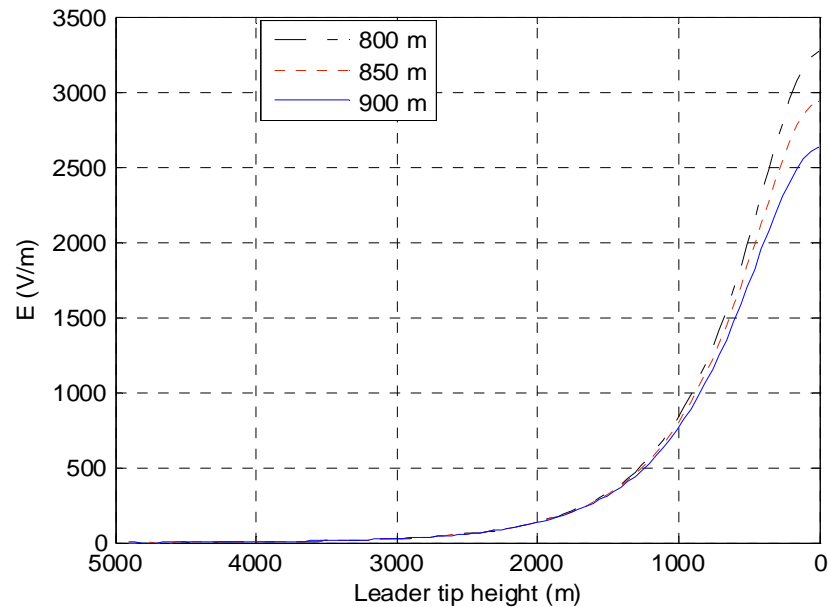

(a)

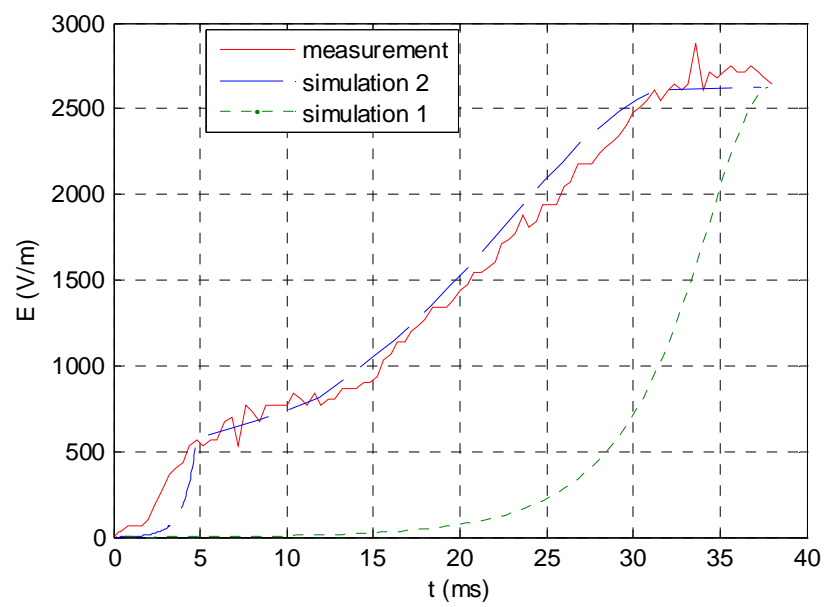

(b)

Fig. (3). Results for Golde - exponencial proposal: (a) Electric field signatures of a downward leader for different distances to the observation points. (b) Measured electric field signature of a downward leader at $900 \mathrm{~m}$ and simulated leaders (1) at constant speed and (2) at variable speed.

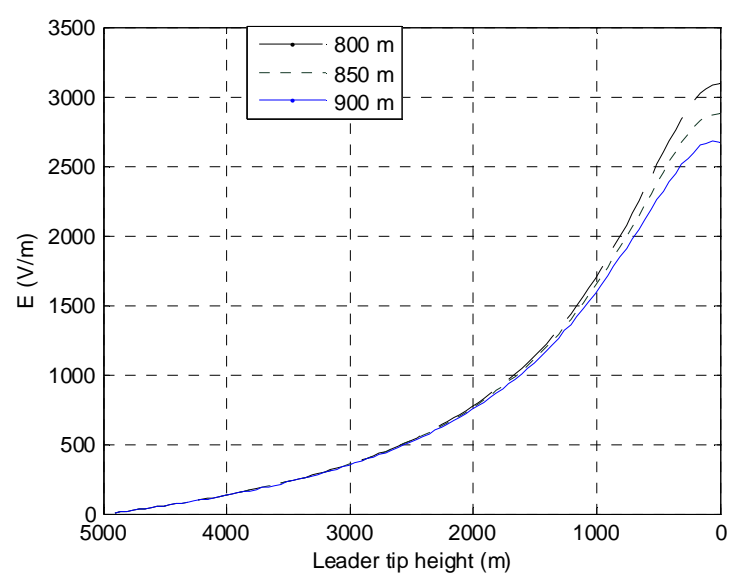

(a)

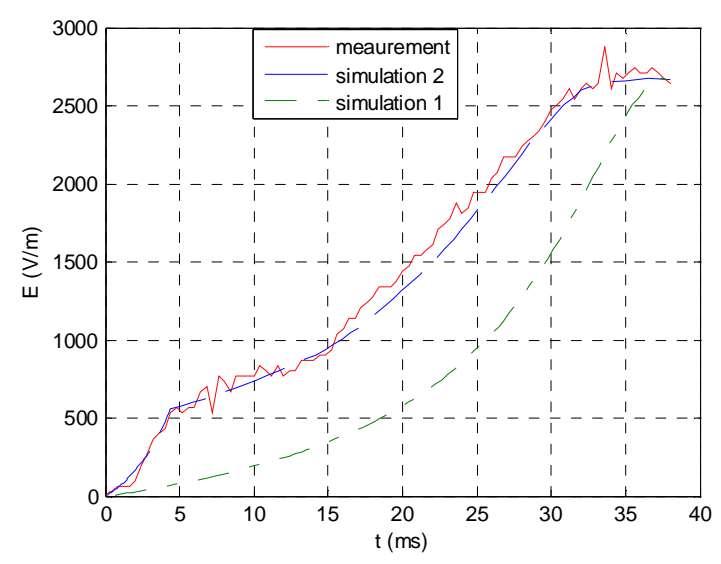

(b)

Fig. (4). Results for Hutzler - uniform distribution proposal: (a) Electric field signatures of a downward leader for different distances to the observation points. (b) Measured electric field signature of a downward leader at $900 \mathrm{~m}$ and simulated leaders (1) at constant speed and (2) at variable speed.

on a point charge at the end of the stepped leader, or on its last stretch of a few tens of meters long. For its part Hutzler [23], proposes a uniform distribution $\left(\rho_{l)}\right.$ and a charge point at the leader tip, whose value depends on the height that is the end of the leader. The total charge in the leader $Q l$ is determined from Equ 10.

$\rho_{l}=\frac{0,9 Q_{l}}{H}$

$q_{0}=0,1 Q_{l}\left(1-\frac{z}{H}\right)$

This means that in the final stage of the leader, contact with the ground, the charge point is $10 \%$ of the total charge transported. Fig. (5) shows the results for electric field variation at ground level for different distances from the observation point and the simulated curves with variable speed for the best results.

\subsection{Dellera's Proposal}

Dellera and Garbagnati [5] in their work on the LPM, suggests the relationship:

$Q_{l}=76 I_{P f}^{0,68} \cdot 10^{-3}$

The LPM model assumes a leader channel maximum length of $2 \mathrm{~km}$, and is based on a uniform distribution of charge from equation 14 .

$\rho_{l}=3,8 \cdot 10^{-5} I_{P f}^{0,68}$

Also at the bottom of the stepped leader, last tens of meters (regardless of the height of the leader), is considered a uniform negative charge of $-100 \mu \mathrm{C}$ (for negative leaders). Fig. (6) shows the results obtained for two cases of study: (a) from the total $Q l$ distributed over the $5 \mathrm{~km}$ length of the leader and (b) considering only the last $2 \mathrm{~km}$ in length, according to the criteria LPM. 


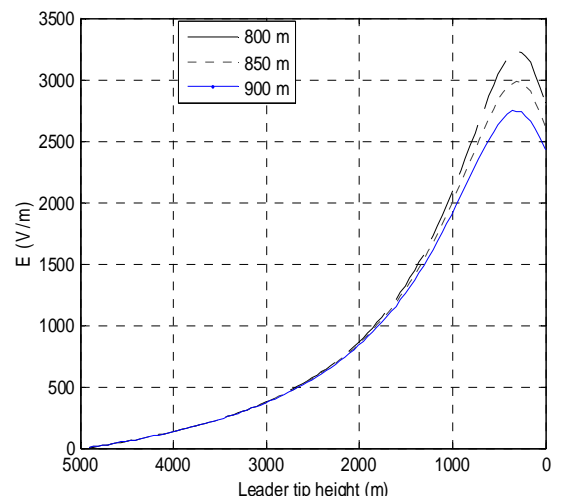

(a)

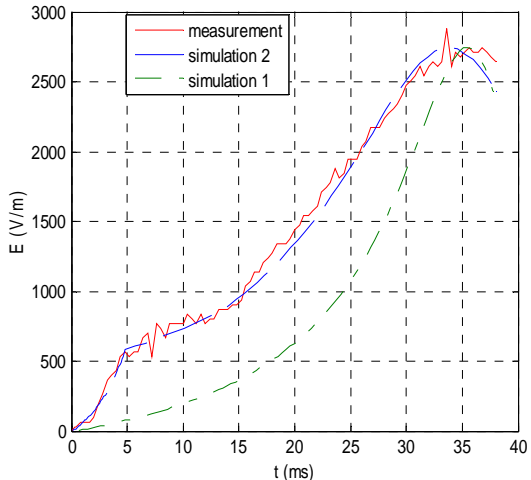

(b)

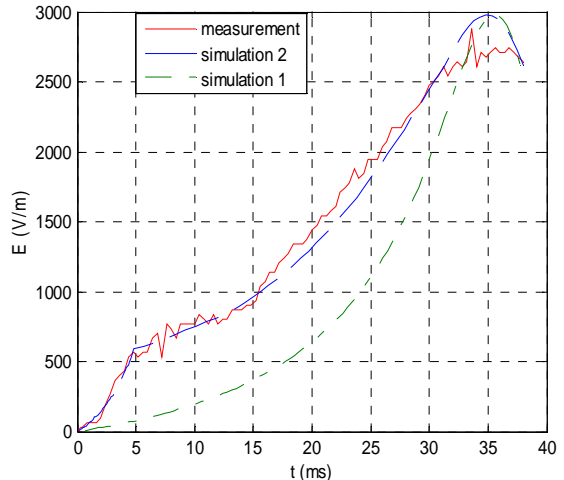

(c)

Fig. (5). Results for Hutzler, uniform + punctual chargue: (a) Electric field signatures of a downward leader for different distances to the observation points. (b) Measured electric field signature of a downward leader at $900 \mathrm{~m}$ and simulated leaders (1) at constant speed and (2) at variable speed. (c) Measured electric field signature of a downward leader at $850 \mathrm{~m}$ and simulated leaders (1) at constant speed and (2) at variable speed.

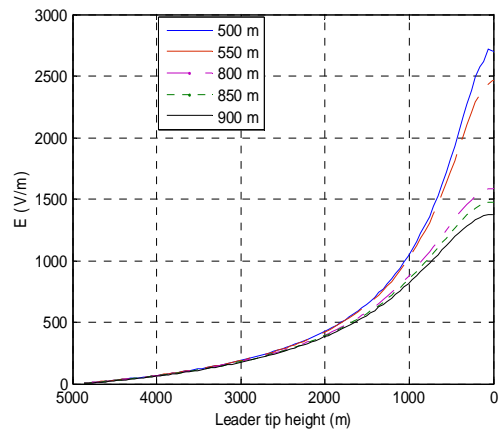

(a)

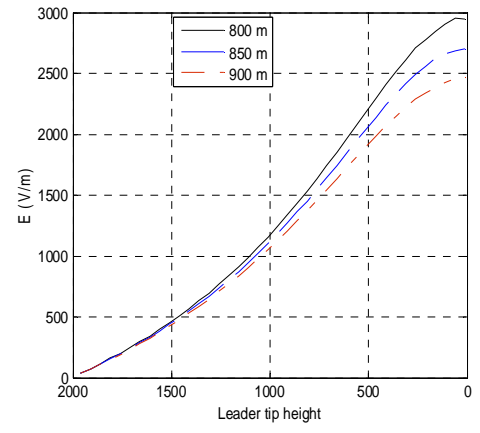

(b)

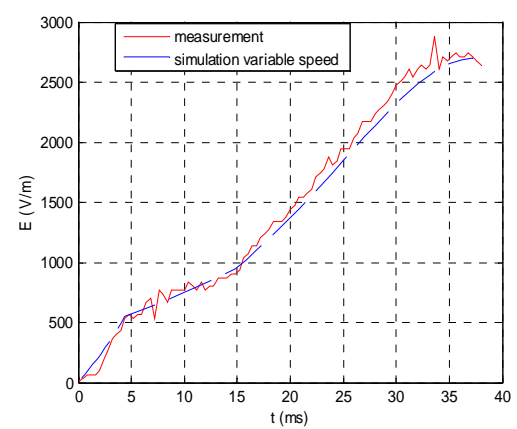

(c)

Fig. (6). Results for LPM model (Dellera /Garbagnati), uniform + segment charge: (a) Electric field signature of a downward leader for $5 \mathrm{~km}$ length. (b) Electric field signature of a downward leader for $2 \mathrm{~km}$ length. (c) Simulation with variable speed for a downward leader $2 \mathrm{~km}$ in length and a point $850 \mathrm{~m}$ away

\subsection{Eriksson's proposal}

Linearly distributed charge along the leader according to the equation,

$$
\rho_{l}=\rho_{l 0}(1-z / H)
$$

Eriksson [25] determines the value of $\rho_{l}$ at the leader end, equation obtained assuming that the distribution in the leader is linear over a channel length of $5 \mathrm{~km}$.

$\rho_{l 0}=3,2 \cdot 10^{-6} I_{P f}^{1,43}$

The charge along the leader at different leader tip heights and the results for $\Delta \mathrm{E}$ at ground level for different distances from the observation point are displayed in Fig. (7).

In this case the best adjust curve to the measured data, is the simulation corresponding to an observation point located $550 \mathrm{~m}$ from the vertical, too far from the estimated true distance.

\section{DISCUSSION}

Best agreements between the measurement and simulations are found with Cooray's proposal $(d=850 \mathrm{~m})$,
Golde's proposal $(\mathrm{d}=900 \mathrm{~m})$, and those of Hutler's proposal $(d=900 \mathrm{~m})$. In the case of Dellera's proposal (LPM), the LPM was initially designed for $\mathrm{H}=2000 \mathrm{~m}$ [5]. If we assume and $\mathrm{H}=5000 \mathrm{~m}$, the best approximation of the experimental measurement and the model is found for a flash distance of $\mathrm{d}=500 \mathrm{~m}$. This distance is not consistent with our observations and the report of the lightning location systems but the deviation may be due regarding that the considered $\mathrm{H}$ is out of the range of the model. A second simulation considering only the last $2000 \mathrm{~m}$ of the leader (higher charge density) agrees with a flash distance of $\mathrm{d}=850 \mathrm{~m}$. This results also a good approach. In the simulation carried out with the Eriksson's proposal, for $\mathrm{H}=5000$, the flash location for a good match between experimental measurement and simulation is about $500 \mathrm{~m}$ to $550 \mathrm{~m}$. These results are not consistent with our observations.

The speed of the simulated leaders in the studied models has been adjusted to in order to best fit to the measured electric field waveform (see Table 1). The average leader speed of the observed flash would correspond to $1.32 \cdot 10^{5} \mathrm{~m} \cdot \mathrm{s}^{-1}$. In most of the models the speed is decreasing from the leader initiation to the ground. The maximum speed is obtained with Hutzler's approach at the initial stage 


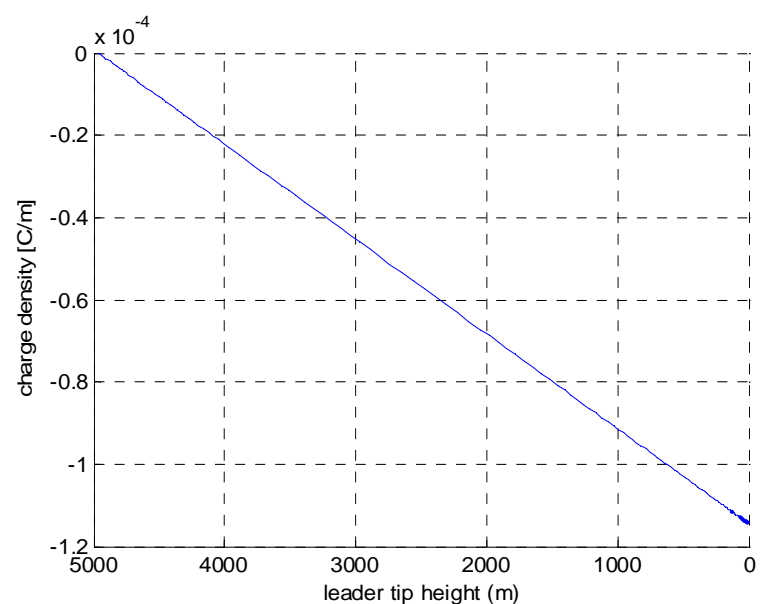

(a)

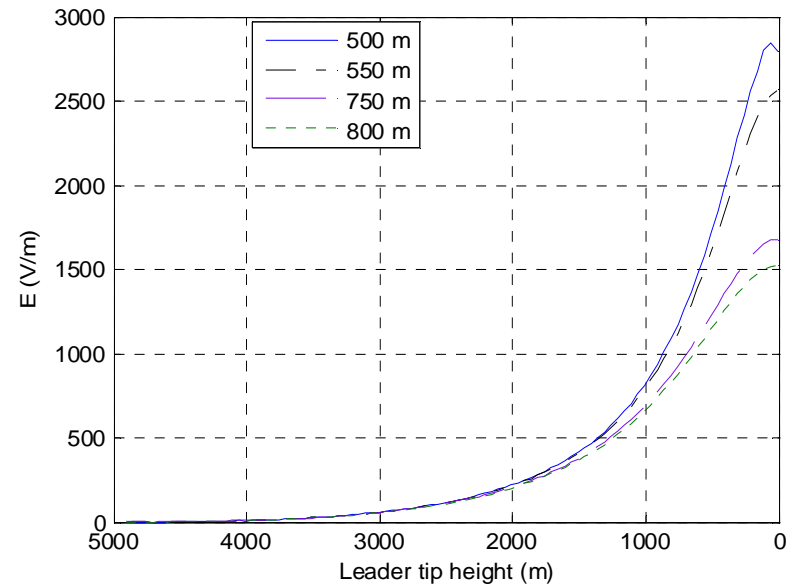

(b)

Fig. (7). Results for Eriksson - lineal proposal: (a) Charge density of the leader at different heights. (b) Electric field signature of a simulated downward leader.

Table 1. Summary of Calculated Stepped Leader Speed

\begin{tabular}{|c|c|c|c|}
\hline $\begin{array}{l}\text { Cooray }(\mathrm{d}=800 \mathrm{~m}) \\
\text { exponential }\end{array}$ & $\begin{array}{c}2.6 \cdot 10^{4} \mathrm{~m} / \mathrm{s} \\
\text { leader tip height }>11 \mathrm{~m}\end{array}$ & $\begin{array}{l}6.6 \cdot 10^{4} \mathrm{~m} / \mathrm{s} \\
\text { lth }>161 \mathrm{~m}\end{array}$ & $\begin{array}{l}1.01 \cdot 10^{6} \mathrm{~m} / \mathrm{s} \\
1 \text { th }>1661 \mathrm{~m}\end{array}$ \\
\hline $\begin{array}{l}\text { Hutzler }(\mathrm{d}=900 \mathrm{~m}) \\
\text { uniform }\end{array}$ & $\begin{array}{l}3.5 \cdot 10^{4} \mathrm{~m} / \mathrm{s} \\
1 \mathrm{th}>11 \mathrm{~m}\end{array}$ & $\begin{array}{l}9.5 \cdot 10^{4} \mathrm{~m} / \mathrm{s} \\
1 \mathrm{th}>211 \mathrm{~m}\end{array}$ & $\begin{array}{l}1.15 \cdot 10^{6} \mathrm{~m} / \mathrm{s} \\
\text { lth }>2411 \mathrm{~m}\end{array}$ \\
\hline $\begin{array}{l}\text { Hutzler }(\mathrm{d}=900 \mathrm{~m}) \\
\text { unif. }+ \text { punctual }\end{array}$ & $\begin{array}{l}7.9 \cdot 10^{4} \mathrm{~m} / \mathrm{s} \\
\text { lth }>11 \mathrm{~m}\end{array}$ & $\begin{array}{l}8.9 \cdot 10^{4} \mathrm{~m} / \mathrm{s} \\
\text { lth }>511 \mathrm{~m}\end{array}$ & $\begin{array}{l}1.1 \cdot 10^{6} \mathrm{~m} / \mathrm{s} \\
\text { lth }>2461 \mathrm{~m}\end{array}$ \\
\hline $\begin{array}{l}\text { LPM }(2 \mathrm{~km}, \mathrm{~d}=850 \mathrm{~m}) \\
\text { (Dellera/Garbagnati) }\end{array}$ & $\begin{array}{l}4.9 \cdot 10^{4} \mathrm{~m} / \mathrm{s} \\
\text { lth }>11 \mathrm{~m}\end{array}$ & $\begin{array}{l}2.9 \cdot 10^{4} \mathrm{~m} / \mathrm{s} \\
\text { lth }>1111 \mathrm{~m}\end{array}$ & $\begin{array}{l}1.34 \cdot 10^{5} \mathrm{~m} / \mathrm{s} \\
\text { lth }>1361 \mathrm{~m}\end{array}$ \\
\hline
\end{tabular}

$\left(1.15 \cdot 10^{6} \mathrm{~m} \cdot \mathrm{s}^{-1}\right)$ and the lower speed is obtained with Cooray's approach at the final stage $\left(2.6 \cdot 10^{4} \mathrm{~m} \cdot \mathrm{s}^{-1}\right)$. We have to point out that the simulations did not consider any structure at the ground neither the final jump. Actually we did not observe any evidence of upward connecting leaders in the observations. In the final stage, the speed values obtained are smaller than those referenced so far [12, 26, 27]. However results are very consistent with that reported recently by Campos et al. [28], with minimum and maximum values recorded for the negative stepped leader of $0.26 \cdot 10^{5} \mathrm{~m} \cdot \mathrm{s}^{-1}$ and $19.8 \cdot 10^{5} \mathrm{~m} \cdot \mathrm{s}^{-1}$ respectively.

\section{CONCLUSIONS}

This paper presented a 3D propagative model of a simplified downward leader. The time domain results in this study shows that the electric field produced by the leader can be very well approached to the measured fields by adjusting the speed and charge. The model also improves the representation of the cloud charges which is estimated from total lightning detections, temperature soundings and volumetric radar.

Cooray's, Golde's and Hutler's proposals are able to match with the measured electric field at consistent distances. In the case of Dellera's (LPM) it certainly adjusts by only considering the last $2 \mathrm{~km}$ of the leader. Eriksson's proposal produced good agreements but closer flash distances. After the models are adjusted, the obtained speeds are consistent with those speeds reported in literature. However, our models and observation do not represent the final jump stage.

\section{ACKNOWLEDGEMENTS}

We are grateful to prof. Carlo Alberto Nucci, prof. Mario Paolone, Marina Bernardi and prof. Alberto Borghetti for their valuable suggestions and cooperation with our group. We also thank to the Spanish MICINN for supporting this study under grant AYA2009-14027-C05-05.

\section{CONFLICT OF INTEREST}

Declared none.

\section{REFERENCES}

[1] Gurevich AV, Zybin KP. Runaway breakdown and electric discharges in thunderstorms. Phys Uspekhi 2001; 44: 1119.

[2] Stolzenburg M, Marshall TC. Charge structure and dynamics in thunderstorms. Space Sci Rev 2008; 137: 355-7.

[3] Williams ER. The tripole structure of thunderstorms. J Geophys Res 1989; 94: 13151-67. 
[4] Vargas M, Cooray V, Becerra M, Torres H. Lightning channel modeling, 28th international conference on lightning protection ICLP. Kanazawa, Japan 2006.

[5] Dellera L, Garbagnati E. Lighting stroke simulation by means of the leader progression model. Part I: description of the model and evaluation of exposure of free-standing structures. IEEE Transact Power Deliv 1990; 5: 2009-22.

[6] Bazelyand EM, Raizer YP. Spark discharge. USA: CRC 1997.

[7] Bernardi M, Dellera L, Garbagnati E, Sartorio G. Leader progression model of lightning: updating of the model on the basis of recent test results, 23rd ICLP. Firenze, Italy 1996.

[8] Rizk F. Modeling of transmission line exposure to direct lightning strokes. IEEE Transact Power Deliv 1990; 5: 4.

[9] Cooray V, Rakov V, Theethayi N. The lighning striking distancerevisited. J Electrostat 2007; 65: 296-306.

[10] Montanyà $\mathrm{J}$, Soula $\mathrm{S}$, Pineda N. A study of the total lightning activity in two hailstorms. J Geophys Res 2007; 112, D13118.

[11] Betz H-D, Marshall TC, Stolzenburg M, et al. Detection of incloud lightning with VLF/LF and VHF networks for studies of the initial discharge phase. Geophys Res Lett 2008; 35: L23802.

[12] Rakov V, Uman M. Lightning: physics and effects. UK: Cambridge University Press 2003. ISBN 0521583276.

[13] Malik N. A Review of the charge simulation method and its applications. IEEE Tansact Electr Insul 1989; $24: 1$.

[14] Zienkiewiez O. The finite element method. New York: McGrawHill 1977.

[15] Janicke L, Kost A. Error estimation and adaptive mesh generation in the 2D and 3D finite element method. IEEE Transact Magn 1996; 32: 3 .

[16] Borghetti A, Napolitano F, Nucci CA, Paolone M, Bernardi M. Numerical solution of the leader progression model by means of the finite element method. 30th ICLP. Cagliari, Italy 2010.
[17] COMSOL Multiphysics. User's Guide Version 3.4. 2007.

[18] Becerra M, Cooray V. A simplified physical model to determine the lightning upward connecting leader inception. IEEE Transact Power Deliv 2006; 21(2): 897-908.

[19] Cooray V. The lightning flash. London, UK: Institution of electrical engineers 2003.

[20] Golde RH. The frequency of occurrence and their distribution of lightning flashes to transmission lines. AIEE Trans 1945; 64: 90210 .

[21] Golde RH. Lightning protection. London: Edward Arnold 1973.

[22] Golde RH. Lightning Vol. 1: Physics of lightning. New York: Academic Press 1977.

[23] Hutzler B. Notes Bibliographiques concernant la simulation en laboratoire des points d'impact de la foudre. Note technique EDF 1988; Ref. HM80-1173.

[24] Berger K, Anderson RB, Kroninger H. Parameters of lightning flashes. Electra 1975; 80: 223-37.

[25] Eriksson A. The lightning ground flash - An engineering study. Ph.D. thesis. Faculty of Engineering, University of Natal. Pretoria, South Africa 1979.

[26] Cooray V. Lightning protection. The Institution of engineering and technology. ISBN 978-0-86341-744-3. London, UK 2010.

[27] Zhang Y, Lu W, Li J, Dong W, Zheng D, Chen S. Luminosity characteristics of leaders in natural cloud-to-ground lightning flashes. Atmos Res 2009; 91: 326-32.

[28] Campos L, Saba M, Warner T, Krider EP, Cummins KL, Orville RE. Does the average downward speed of a lightning leader change as it approaches the ground? - An observational approach. 21 st International Lightning Detection Conference. Orlando, Florida, USA 2010.

(C) Hermoso et al.; Licensee Bentham Open.

This is an open access article licensed under the terms of the Creative Commons Attribution Non-Commercial License (http://creativecommons.org/licenses/by-nc/3.0/) which permits unrestricted, non-commercial use, distribution and reproduction in any medium, provided the work is properly cited. 